\title{
A Revista Infância e Juventude e os debates em torno do Plano Nacional de Educação de 1936 a 1937
}

The Infância e Juventude Magazine and the debates around the National Education Plan from 1936 to 1937

La Revista Infância e Juventude y los debates en torno al Plan Nacional de Educación de 1936 a 1937

\author{
Sônia Camara \\ Universidade do Estado do Rio de Janeiro (Brasil) \\ http://orcid.org/0000-0003-0255-697X \\ http://lattescnpq.br/6303435255974589 \\ soniacamarauerj@gmail.com \\ Cinthya de Oliveira Nunes \\ Universidade do Estado do Rio de Janeiro (Brasil) \\ http://orcid.org/0000-0001-8582-2713 \\ http://lattes.cnpq.br/5210545260479574 \\ cinthya.nunes14@gmail.com
}

\section{Resumo}

$\mathrm{O}$ artigo objetiva analisar as ideias que, publicadas na Revista Infância e Juventude, colaboraram na promoção de debates em torno da elaboração do projeto do Plano Nacional de Educação durante os anos de 1936 a 1937. Constituindo-se em um periódico mensal a serviço da escola e do lar, a revista circulou de maio de 1936 a dezembro de 1937, congregando em seus quadros intelectuais educadores envolvidos com a produção de reflexões acerca de temas candentes à educação brasileira. Para efeito deste artigo, interessa captar a participação dos intelectuais, partícipes da Associação Brasileira de Educação (ABE), que utilizaram a revista como veículo de difusão e construção de opinião, veiculando concepções e tomando posição em defesa da educação e da cultura nacional.

Palavras-chave: Revista Infância e Juventude. Plano Nacional de Educação. História da Educação. 


\begin{abstract}
The article aims to analyze the ideas published in the Infância e Juventude Magazine, which contributed to the promotion of debates about the elaboration of the project of the National Plan of Education during the years 1936 to 1937. It is a monthly newspaper in the service of the school and the home, the magazine circulated from May 1936 to December 1937, bringing together in its intellectual frameworks educators involved with the production of reflections on themes that are burning with Brazilian education. For the purpose of this article, we are interested in capturing the participation of intellectuals, members of the Brazilian Association of Education (ABE), who used the magazine as a vehicle for dissemination and opinion building, conveying concepts and taking a position in defense of education and national culture.
\end{abstract}

Keywords: Infância e Juventude Magazine. National Education Plan. History of Education.

\title{
Resumen
}

El artículo objetiva analizar las ideas que, publicadas en la Revista Infância e Juventude, colaboraron en la promoción de debates en torno a la elaboración del proyecto del Plan Nacional de Educación durante los años de 1936 a 1937. Constituyéndose en un periódico mensual al servicio de la escuela y del hogar, la revista circuló de mayo de 1936 a diciembre de 1937, congregando en sus cuadros intelectuales educadores involucrados con la producción de reflexiones acerca de temas candentes a la educación brasileña. A efectos de este artículo, nos interesa captar la participación de los intelectuales, participes de la Asociación Brasileña de Educación (ABE), que utilizaron la revista como vehículo de difusión y construcción de opinión, vehiculando concepciones y tomando posición en defensa de la educación y la cultura nacional.

Palabras clave: Revista Infância e Juventude. Plan Nacional de Educación. Historia de la Educación. 
Aos educadores e às entidades educacionistas de todo o Brasil. $\mathrm{O}$ ardente desejo que temos de fazer deste mensário um eficiente órgão nacional de exame e de divulgação de todas as atividades do país, relacionadas com o problema educacional, anima-nos a apelar para o vosso concurso, pois só com o apoio da pequena minoria dos que podem sentir as grandes necessidades do Brasil é que conseguiremos vencer a indiferença geral do povo, grave dificuldade que esmorece a ação educacional, por mais abnegados, que sejam os seus propulsores. Contamos que vossa solidariedade com nossos objetivos se manifeste na indispensável contribuição material da assinatura, sem a qual será impossível manter-se uma publicação seria e digna dos altos fins a que sinceramente nos dedicamos. Os Diretores. (INFÂNCIA E JUVENTUDE, n. 3, 1936 - grifos da Revista).

\section{Introdução}

Criada em junho de 1936, a Revista Infância e Juventude veio a lume tendo como intuito ser um mensário nacional de orientação pedagógica da escola e do lar. Com redação na cidade do Rio de Janeiro, capital do país, a revista foi editada nas Oficinas Gráficas de Infância e Juventude, de propriedade de Renato Americano, fundador, diretor responsável e editor da revista. Além de sua publicação, a gráfica realizava impressões de livros, edições de vários gêneros e coleções, a exemplo da Série Pindorama. Ao longo do período que circulou, de junho de 1936 a dezembro de $1937^{1}$, foram produzidos dezoito números da revista com aproximadamente cinquenta e cinco páginas por exemplar e com valor de assinatura anual simples de $18 \$ 000$, registrada de $22 \$ 000$, avulsa de $2 \$ 000$ e atrasada de $3 \$ 000$. A proposta tipográfica da revista seguia um padrão simples de diagramação, com capa em única cor, nome da revista com letras destacadas no cabeçalho e, acima a frase: "Mensário de orientação pedagógica na escola e no lar". Na parte inferior, centralizado e grifado os nomes dos seus colaboradores. O título da revista, por sua vez, parece-nos sugestivo quando analisado em sintonia com a frase aludida acima. Concebidas como provir, a infância e a juventude, deveriam ser educadas e instruídas a fim de inscreverem as possibilidades de um futuro glorioso para a nação. Esta crença arregimentada em torno da capacidade regeneradora da educação conformou os objetivos que mobilizaram a criação da revista no contexto de efusivos debates associados à construção do país e de sua nacionalidade (CAMARA, 2013).

Em sua composição editorial, a revista constituiu-se com seções e colunas destinadas a discutir temáticas relativas à educação e à política nacional, sem a utilização de ilustração. Nas edições analisadas não foi possível localizar a tiragem e as regiões em que circulou regular ou irregularmente. Propagandas de livros e de jornais, a exemplo do Diário de Notícias, da Folha

\footnotetext{
${ }^{1}$ Consideramos este período em função dos exemplares identificados no setor de periódico da Biblioteca Nacional. Foram localizados dezesseis exemplares, a contar do número três, de agosto de 1936 e o último de 19 de dezembro de 1937. Os números dezessete e dezoito foram publicados em edição condensada de outubro/novembro de 1937.
} 
de Minas, bem como da Papelaria Casa Cruz, da Casa Sucena, do Banco do Brasil, da Fazenda Manga Larga, do Curso Victor Silva, do Instituto Lafayette, do programa Chiquinho, Chicote e Chicória ${ }^{2}$ transmitidos nas estações das rádios Record e Excelsior dão indícios do público que se pretendia atingir com a publicação. A revista foi concebida como um mensário destinado a debater e fazer circular ideias em torno da educação em um contexto que requisitava dos intelectuais uma tomada de posição em prol da construção de um projeto nacional.

Quanto ao corpo editor ${ }^{3}$, importa destacar a crescente participação do proprietário Renato Americano. A partir da terceira edição, publicada em agosto de 1936, é possível identificar a presença de Americano exercendo, concomitantemente, as funções de editor fundador e de diretor administrativo da revista até a sua extinção em dezembro de 1937, um mês após a instauração do Estado Novo. Do corpo diretor colaboraram, por um curto período de tempo, Joaquim Moreira de Souza, como diretor técnico e Stella Aboim, como secretaria. Professora de História Natural e de Desenho da Liga dos Professores da Capital do País, Stella Aboim envolvida com questões associadas à educação e ao magistério. Quanto ao professor Joaquim Moreira de Souza foi membro da Diretoria Nacional de Educação, atuando como diretor de instrução pública do Ceará, em 1934. Neste ano participou da coordenação da $6^{\circ}$ Conferência Nacional de Educação ocorrida em Fortaleza (CAVALCANTE, 2000). Na revista, representou a Diretoria Nacional de Educação em muitas publicações em que expôs propostas de metodologia de ensino para as escolas rurais. Sobre Renato Americano não foi possível localizar indícios que permitisse articulá-lo a grupos de professores ou movimentos sociais, diferentemente de Joaquim Moreira de Souza e Stella Aboim, figuras engajadas em várias frentes de atuação e debates acerca da educação ao longo da década de 1930.

Com base nestas reflexões iniciais, o artigo tem como intenção analisar a Revista Infância e Juventude tencionando refletir acerca dos debates em torno do Plano Nacional de Educação produzidos pelos intelectuais, partícipes da Associação Brasileira de Educação (ABE), durante o período em que circulou, de 1936 a 1937. Tencionamos identificar as linhas de força que alimentaram esses debates, bem como as motivações e concepções que balizaram a composição do Plano Nacional de Educação, exigida pela Constituição de 1934. O protocolo acionado pela pesquisa abarcou o mapeamento, a seleção e a leitura das edições da revista, localizadas no setor de periódicos da Biblioteca Nacional, em particular dos números em que o Plano Nacional de Educação foi abordado direta ou indiretamente. Com este intento foram identificadas vinte entradas, sendo: uma referente a artigo em que a temática aparece de forma indireta; três referentes à publicação do projeto do Plano Nacional de Educação, apresentado em 1826, que foi desmembrado por números consecutivos da revista durante o ano de 1936 e dezesseis em que o Plano Nacional de Educação assumiu centralidade no título dos artigos.

A par destas referências, o texto desenvolve-se demarcado por duas premissas centrais e correlatas: a primeira, de que a revista funcionou como canteiro de sociabilidades, de disseminação e de debates em torno da educação nacional, com destaque para as discussões em torno da elaboração do Plano Nacional de Educação; a segunda, de que as ideias veiculadas pela revista expressavam as aspirações de setores intelectuais em um esforço destinado a potencializar projetos para a educação do país.

\footnotetext{
${ }^{2}$ Programa concebido por Nhô Totico, cognome de Vital Fernandes da Silva, foi transmitido, a partir de 1934, pela Rádio Record. Tinha como cenário a Escolinha de Dona Olinda em que eram narradas as histórias. A partir do universo de três meninos: Chiquinho, menino da cidade e inteligente; Chicote, menino nordestino e valentão e Chicória, filho de imigrante italiano eram retratados aspectos da sociedade brasileira visando construir interpretações sobre a educação e o país com seus regionalismos transvertidos de adjetivações expressas nas características dos personagens. http:/baudomaga.com.br/humor, acesso 21/08/2016.

${ }^{3}$ Foram localizadas escassas informações sobre o proprietário e fundador Renato Americano, bem como do corpo editor da revista.
} 


\section{Revista Infância e Juventude como canteiro dos debates educacionais}

O movimento civil-militar que culminou com a "Revolução de 1930" colocou fim à política das oligarquias principiando a chamada Republica Nova, chefiada pelo presidente Getúlio Vargas. A sua posse deu início a denominada "Era Vargas" ${ }^{4}$ (1930-1945), período de efervescência política marcada pelos conflitos de interesses que caracterizou os anos que antecederam a sua posse em novembro de 1930. Na disputa pela preeminência política no período pós-revolução, estratégias foram instituídas objetivando compor e consolidar um projeto nacional. Conforme Pandolfi (2012, p. 17-18) essas disputas ocorreram "em torno do modelo de Estado a ser implantado no país", onde os tenentes e os "oligarcas dissidentes" propunham, em comum, a atuação de um Estado centralizador e intervencionista. Neste particular, segundo a autora, corporificou-se uma matriz de cunho nacionalista e intervencionista por parte do Estado a partir da organização de investimentos em diferentes esferas, com destaque para o social. Estes investimentos foram encaminhados, especialmente, a partir da atuação e das ações empreendidas pelos ministérios do Trabalho, Indústria e Comércio com o jornalista Lindolfo Collor e da Educação e Saúde Pública, com o educador e reformador mineiro Francisco Campos, a partir de novembro de $1930^{5}$.

Sob a vigência da Carta Constitucional de julho de 1934, ocorreram avanços sociais e políticos, a exemplo do voto secreto, do voto feminino, da obrigatoriedade do ensino primário, da eleição presidencial por meio do voto da Assembleia Constituinte (POLLETI, 2012, p. 36), bem como da criação do Conselho Nacional de Educação (CNE) e a obrigatoriedade de se "destinar um percentual dos impostos para a educação" (CURY, 2014). No entanto, com o estabelecimento do Estado Novo (1937 a 1945), a Constituição foi suspensa, sendo outorgada uma nova carta constitucional de perfil centralizador e autoritário, em 1937. Este aspecto marcou de forma determinante a política nacional a partir de então. Nesta perspectiva, afirma Capelato (2012) que:

Uma das soluções propostas era a do controle social através da presença de um Estado forte comandado por um líder carismático, capaz de conduzir as massas no caminho da ordem. Essa política foi adotada em alguns países europeus, assumindo características específicas em cada um deles. Regimes como o fascismo na Itália, o nazismo na Alemanha, o salazarismo em Portugal e o franquismo na Espanha foram constituídos nesta época. O sucesso das experiências italianas e alemães serviu de inspiração para reformas políticas que ocorreram em alguns países latino-americanos: Brasil e Argentina especialmente (2012, p. 109).

Neste contexto, deu-se o florescimento cultural expresso, em parte, pela proliferação de jornais, revistas e editoras que se associavam às iniciativas destinadas a colaborar para a reconstrução nacional. Como canteiro de difusão dos projetos de intervenção político e pedagógico, grosso modo, é possível assegurar que as revistas constituíram-se em espaços de disputas, sociabilidades e veiculação de ideias. No que tange a Revista Infância e Juventude,

\footnotetext{
${ }^{4}$ A Era Vargas é dividida em três períodos: de 1930 a 1934, conhecido como Governo Provisório; de 1934 a 1937, Governo Constitucionalista e de 1937 a 1945, Estado Novo. Capelato (2012), por sua vez, trabalha com a perspectiva de que a primeira fase do governo Vargas se dividiu em dois períodos: de 1930 a 1937, considerado anos de indefinição e momento de disputas de projetos distintos para o país e de 1937 a 1945, como a vigência de um novo regime.

${ }^{5}$ Desde a criação do Ministério da Educação e Saúde Pública, em novembro de 1930 até o término da "Era Vargas", em 30 de outubro de 1945, a pasta foi ocupada por quatro ministros, tendo Gustavo Capanema permanecido por onze anos no cargo. A presença de Francisco Campos à frente do ministério contribuiu, consideravelmente, para a posição estratégica que a educação passou a assumir no governo Vargas.
} 
esta foi concebida como periódico especializado, com fins pedagógicos, sem fins econômicos e sem relação direta com partidos e congregações políticas e de caráter neutro. Deste modo, asseguravam seus idealizadores que:

Esta revista, absolutamente isenta de qualquer sectarismo e dentro de um espírito de ampla tolerância, tem por única e sincera finalidade o estudo das questões que, sob qualquer aspecto se relacionem com a educação de nossa mocidade. Encontra-se neste campo neutro, a liberdade indispensável aos verdadeiros estudiosos das ideias pedagógicas, cujas opiniões aparecerão sem nenhum constrangimento, dentro dos razoáveis limites da ética e sob a imensa responsabilidade de cada qual. Não havendo, aqui, incompatibilidade de nomes, as reservas que porventura tenhamos de opor aos trabalhos recebidos visarão exclusivamente manifestas impropriedades de assunto e nunca simplificarão ocultas restrições e pessoas (INFÂNCIA E JUVENTUDE, 1936, n. 6, p. 364).

Procurando marcar o perfil de imparcialidade, isenção e comprometimento com as questões atinentes à educação nacional, os editores da Revista Infância e Juventude apresentaram-na como um periódico educacional, dedicado à divulgação pedagógica e à disseminação das ideias e ações dos intelectuais, professores e instituições científicas e educacionais. Embora seus editores objetivassem assinalar o caráter de isenção e neutralidade, observamos nos textos analisados, um forte engajamento em torno da educação liberal, com destaque para o seu papel na reconstrução nacional sob a intervenção do Estado. A revista fez circular artigos cujos autores assumiram posições diante do crescimento de correntes intelectuais antiliberais em alerta para o crescimento dos movimentos sociais e políticos que eclodiram a partir da Revolução Russa de 1917. Como demonstra Capelato (2012), a questão social passou a ser debatida intensamente no país. Associada a ela fomentaram-se ideias em torno da incapacidade das instituições liberais para "vencer o 'atraso' e controlar a 'desordem' reinante no país" (2012, p. 110).

Nesta direção, ressalta Carvalho (1997), que a campanha educacional empreendida pelos integrantes da Associação Brasileira de Educação (ABE) produziu o que denominou de "taineana temperatura moral" que visou combater a "pretextada incapacidade das elites políticas brasileiras, indiferentes ou céticas quanto à necessidade, à possibilidade e à eficácia de operar a regeneração do homem brasileiro". Importa considerar, ainda, que diante da organização do movimento católico, expresso por um "radicalismo ultraconservador", mobilizou-se uma reação por parte dos intelectuais educadores que defendiam a bandeira da educação nacional, laica e gratuita na composição de dispositivos capazes de instituir a ideia do "progresso dentro da ordem" (1997, p. 121-122).

Com intuito de divulgar propostas e produzir opinião, a Revista Infância e Juventude coligou contribuições de representantes do magistério do Distrito Federal e de outras regiões do país quanto aos rumos da educação nacional. A tomada de posição expressa nos escritos, marca a compreensão, por parte dessa elite intelectual, acerca do papel histórico assumido, por eles, como guias capazes de interferir na direção política do país. Como afiança Velloso (2012), o cenário que se descortinou no país no pós Revolução de 1930 e os rumos assumidos pela política nacional "solicitavam" a participação dos intelectuais identificados como "consciência iluminada do nacional e o Estado como cerne da nacionalidade" (2012, p. 148).

A análise dos sumários das revistas permite inventariar não somente a participação direta de associações e de uma plêiade de intelectuais, como também um leque variado de temas que foram mobilizados ao longo das edições. Nos dezoito números publicados, a revista 
contou com colaboradores efetivo e flutuante. Na categoria de flutuante identificamos um número aproximado de noventa e sete colaboradores, entre eles: Afrânio Peixoto, Isaias Alves, Alba Canizares, Leoni Kaseff, Heitor Villa Lobos, Renato Kehl, J. Moreira de Souza, Sebastião Mascarenhas, Orminda Isabel Marques, Lourenço Filho, Gustavo Capanema, Francisco Venâncio Filho, Dulce Botelho. Alguns desses intelectuais, a partir da quarta edição da revista, de 1936, passaram a compor o quadro de colaboradores efetivos, a exemplo de Afrânio Peixoto (Associação Brasileira de Educação e Universidade do Distrito Federal), Isaias Alves (Conselho Nacional de Educação), Leoni Kaseff (Assistente técnico da Universidade do Brasil), Maria dos Reis Campos (Escola de Educação da Universidade do Distrito Federal), Teixeira de Freitas (Diretor de estatística do Ministério da Educação) e Helena Antipoff (Escola de aperfeiçoamento de Belo Horizonte), entre outros nomes.

Destes colaboradores efetivos, destacaram-se na escrita sobre o Plano Nacional de Educação: Isaias Alves, Leoni Kaseff e M. A. Teixeira de Freitas; quanto aos flutuantes, Gustavo Capanema, Reynaldo Porchat e Padre Arlindo Vieira. Quanto às instituições que se posicionaram sobre o Plano Nacional de Educação, destaque assumiram a Associação Brasileira de Educação (ABE), com três artigos e o Instituto Histórico e Geográfico Brasileiro (IHGB), com um, perfazendo um total de vinte artigos. Parece-nos plausível afirmar que a circulação desses artigos, no contexto das discussões em torno do anteprojeto do Plano, constituiu-se como ação estratégica (CERTEAU, 2011) mobilizada pelos intelectuais colaboradores da revista, no sentido de debater ideias e fazer repercutir as concepções que defendiam e, assim, pautar os temas que deveriam compor o Plano Nacional de Educação.

Quadro dos colaboradores efetivos e flutuantes que escreveram sobre o Plano Nacional de Educação

\begin{tabular}{|c|c|c|c|}
\hline Nome & Instituição & Título dos artigos & Ano/ edição/ \\
\hline $\begin{array}{l}\text { Associação } \\
\text { Brasileira de } \\
\text { Educação }\end{array}$ & $\begin{array}{l}\text { Associação Brasileira } \\
\text { de Educação (ABE) }\end{array}$ & $\begin{array}{l}\text { O Plano Nacional de Educação; } \\
\text { A educação acessível aos } \\
\text { necessitados - comunicado da } \\
\text { ABE; } \\
\text { O novo diretor do departamento } \\
\text { nacional de educação. }\end{array}$ & $\begin{array}{l}1936 / 3 \\
1937 / 7 \\
1937 / 12\end{array}$ \\
\hline Sem autoria & Sem identificação & $\begin{array}{l}\text { Um Plano Nacional em 1826; } \\
\text { Um Plano Nacional em } 1826 \\
\text { (continuação); } \\
\text { Um Plano Nacional em } 1826 \\
\text { (continuação). }\end{array}$ & $\begin{array}{l}1936 / 3 \\
1936 / 4 \\
1936 / 5\end{array}$ \\
\hline Basílio Magalhães & $\begin{array}{l}\text { Instituto Histórico e } \\
\text { Geográfico Brasileiro }\end{array}$ & Plano Nacional de Educação. & 1937/8 \\
\hline Gustavo Capanema & Ministro da Educação & Conselho Nacional de Educação. & $1937 / 9$ \\
\hline Redação & Infância e Juventude & $\begin{array}{l}\text { O ensino na zona rural; } \\
\text { Pelo Ministério da Educação; } \\
\text { Conselho Nacional de Educação; } \\
\text { Plano Nacional de Educação. }\end{array}$ & $\begin{array}{l}1936 / 3 \\
1936 / 3 \\
1937 / 11 \\
1937 / 12\end{array}$ \\
\hline Isaias Alves & $\begin{array}{l}\text { Conselho Nacional de } \\
\text { Educação }\end{array}$ & $\begin{array}{l}\text { O Ensino Profissional e o Plano } \\
\text { Nacional de Educação; } \\
\text { Educação de Adultos no Plano } \\
\text { Nacional de Educação. }\end{array}$ & $\begin{array}{l}1936 / 4 \\
1936 / 5\end{array}$ \\
\hline Leoni Kaseff & $\begin{array}{l}\text { Assistente técnico da } \\
\text { Universidade do Brasil }\end{array}$ & $\begin{array}{l}\text { Plano Nacional de Educação - suas } \\
\text { oportunidades e objetivos } \\
\text { primaciais; } \\
\text { O ensino emendativo no Plano } \\
\text { Nacional de Educação - sugestões } \\
\text { para um anteprojeto. }\end{array}$ & $\begin{array}{l}1936 / 6 \\
1937 / 12\end{array}$ \\
\hline
\end{tabular}




\begin{tabular}{|l|l|l|l|}
\hline \multicolumn{1}{|c|}{ Nome } & \multicolumn{1}{|c|}{ Instituição } & \multicolumn{1}{c|}{ Título dos artigos } & Ano/ edição/ \\
\hline Reynaldo Porchat & $\begin{array}{l}\text { Conselho Nacional de } \\
\text { Educação }\end{array}$ & Conselho Nacional de Educação. & $1937 / 11$ \\
\hline Pe. Arlindo Vieira & Igreja Católica & A reforma do ensino secundário. & $1937 / 12$ \\
\hline Teixeira de Freitas & $\begin{array}{l}\text { Diretor de estatística } \\
\text { do Ministério da } \\
\text { Educação }\end{array}$ & $\begin{array}{l}\text { A atuação do ministro Capanema e } \\
\text { a nova fase do Departamento } \\
\text { Nacional de Educação; } \\
\text { A propósito do Plano Nacional de } \\
\text { Educação. }\end{array}$ & $1937 / 11$ \\
\hline
\end{tabular}

Fonte: Elaborado a partir da análise das revistas publicadas entre os anos de 1936 a 1937.

Nos números examinados identificamos diversos temas, como: ensino da zona rural, práticas escolares, instituições escolares, arte, higiene, metodologias no ensino, ensino primário, ensino secundário, o Conselho Nacional de Educação (CNE), educação de adultos, literatura infantil, educação doméstica e profissional, testes escolares, eugenia, civismo e recursos pedagógicos. Até a revista de número doze, publicada em maio de 1937, por ocasião do seu primeiro aniversário, foram discutidos temas relacionados ao Plano Nacional de Educação, o Conselho Nacional de Educação, as metodologias de ensino primário na zona rural, as endemias rurais, a literatura infantil, os recursos para as ciências naturais e matemática, entre outros. A partir da décima terceira revista, percebe-se uma abordagem voltada para a infância, a alfabetização, a leitura com ênfase para o primeiro ano do ensino primário, a literatura infantil, os fundamentos do ensino secundário e a higiene escolar. Após o primeiro ano de atividade não foram localizados artigos alusivos ao Plano Nacional. O que em nossa compreensão está associado, em parte, ao fato da proposta do Plano ter sido, em fevereiro de 1937, apresentado pelo CNE e já se encontrar em tramitação nas instâncias governamentais responsáveis pela sua votação. A perspectiva em torno da discussão acerca do papel e da finalidade que deveria assumir o Plano - diretriz ou código na configuração da educação nacional perdeu força e significação diante da imposição do Estado Novo a partir de dezembro de 1937.

Analisando a importância dos impressos na escrita da História dos, e por meio dos periódicos, Luca (2014, p. 133-134) salienta que estes tinham como função social interpor-se às discussões ensejando provocar intervenções no social, aspecto que marcou os mensários que objetivavam constituir-se como construtores de opinião. Deste modo, o caráter doutrinário e de intervenção caracterizou "a imprensa brasileira de grande parte do século XIX". Em acordo com esta compreensão, consideramos que esse perfil de intervenção social propagou-se para o século XX, assumindo forma, com a criação da Revista Infância $e$ Juventude. Destarte a autora esteja se referindo a uma imprensa de caráter comercial e de circulação para um público mais amplo, ponderamos que sua análise coopera na análise da Revista Infância e Juventude e no que identificamos como sendo uma marca do seu engajamento à causa da educação. Nesta direção, a pertença dos intelectuais colaboradores, bem como o perfil editorial da revista parece-nos indicativos relevantes quanto ao caráter doutrinário e de intervenção assumido pelo impresso.

Deste modo, a revista Infância e Juventude procurou divulgar informações e debater ideias por meio de suas seções, como: Política, Cultura, Prática escolar, Instituições escolares, Arte, Instruindo e divulgando, Várias, Higiene, Ruralismo, Bibliografia, Legislação, Registro, Práticas escolares, Planos e métodos, entre outras. Exemplar era a seção Legislação em que seus editores buscavam demonstrar o andamento das leis e projetos, como o Veto ao Projeto de Lei que dispensava do curso suplementar os estudantes do ensino secundário, publicado na revista de agosto de 1936; a Circular número 200 de $1^{\circ}$ de junho de 1932 do Ministério de Educação e Saúde Pública - Departamento Nacional de Educação, de 
junho de 1937; a Lei №452 de julho de 1937, que organizava a Universidade do Brasil, entre outros. Ao longo dos dezoito números que publicou a revista não manteve seções fixas. Ao analisar os números, identificamos um perfil editorial que poderia ser agrupado em quatro momentos. No primeiro, do número um ao três, a revista apresentou seções de: Política, Cultura, Prática escolar, Instituições escolares, Arte, Instruindo e divulgando, Várias, Higiene, Ruralismo, Registro, Bibliografia e Legislação; no segundo, a partir do número quatro ao dez, identificamos as seções: Registro e Bibliografia; no terceiro, a partir do número onze e doze em que algumas edições passaram a contar com as seções: Instruindo $e$ divulgando, Registro ou Bibliografia e, em alguns casos, com ambas; no quarto momento, localizado na décima terceira revista percebemos a ausência dessas seções e a inclusão das seções Crônicas, Planos e métodos, Assuntos Gerais, Legislação e Registro, mantendo esse perfil editorial até o último número.

Assim anunciando e debatendo questões, a revista constituiu-se como espaço privilegiado de difusão de ideias em torno da educação em âmbito nacional, com destaque para os artigos que aludiam à necessidade e o caráter que deveria assumir o Plano Nacional para a educação. Esta perspectiva foi defendida a partir das participações de Leoni Kaseff, Teixeira de Freitas, Basílio Magalhães e Isaias Alves, Reynaldo Porchat, bem como do ministro da Educação Gustavo Capanema e do padre Arlindo Vieira ${ }^{6}$.

\section{Debates em torno do Plano Nacional e sua elaboração: ideias em disputa}

Criado, a partir do Decreto 19.850, de 11 de abril de 1931, o Conselho Nacional de Educação (CNE) foi concebido como órgão consultivo do Ministério da Educação e Saúde Pública no que se referia aos assuntos relativos ao ensino. Entre as atribuições do CNE, previa-se a de "firmar as diretrizes gerais do ensino primário, secundário, técnico e superior, atendendo, acima de tudo, os interesses da civilização e da cultura do país" (DIÁRIO OFICIAL, 4/6/1931, p. 9210). Para isto, ficou estabelecido que se criasse comissões encarregadas de preparar e redigir um plano nacional a ser submetido ao Governo da República e dos estados (CURY, 2011). Nos debates realizados no Conselho Nacional de Educação, neste ano, a prerrogativa proposta pelo conselheiro João Simplício Carvalho (CURY, 2015, p. 403) caminhava na direção de que o Plano deveria:

[...] satisfazer as exigências da atualidade brasileira, tomando em consideração as condições sociais do mundo, e assegurará, pela sua estrutura e pela sua aplicação, o fortalecimento da unidade brasileira, o revigoramento racial de sua gente e o despertar dos valores indispensáveis ao seu engrandecimento econômico; e, depois de estudado e aprovado pelo Conselho Nacional de Educação, será submetido ao exame do Governo da República e à consideração dos Governos dos Estados. E estabelecerá, apanhando todos os aspectos do Problema educativo [...] (CARVALHO apud CURY, 2015, p. 404).

Assim, a Constituição de 1934, retomou o Decreto de 1931 estabelecendo em seu artigo 150, a exigência do Conselho Nacional de Educação elaborar um plano nacional para o "ensino de todos os graus e ramos, comuns e especializados", coordenando e fiscalizando a "sua execução, em todo o país" (artigo 150 apud CURY, 2015, p. 397). Para isto, o Plano Nacional de Educação seria de competência da União e atribuição do Conselho Nacional de Educação. Ao primeiro cabia fixar, coordenar e fiscalizar sua execução e, ao segundo,

\footnotetext{
${ }^{6}$ Quanto às posições assumidas pelos intelectuais católicos, conferir o trabalho de Skalinski Junior e Ruckstadter (2016).
} 
promover a sua elaboração. Assim, a partir da Lei 174 de 1936 foi instalado o Conselho Nacional de Educação e, com ele, a Portaria de número 15/37 que criava uma comissão encarregada de elaborar, em noventa dias, o Plano Nacional de Educação (CURY, 2015, p. 409). A comissão era composta pelos conselheiros: Samuel Libânio, Aníbal Freire e Reinaldo Porchat, responsável por presidir o CNE (2015, p. 405).

No discurso de instalação do Conselho Nacional de Educação, proferido pelo ministro Gustavo Capanema, em 16 de fevereiro de 1936, observa-se, por um lado, um tom de crítica ao caráter "fragmentário" e "incompleto" das leis vigentes no país. Por outro, uma visão perspectivada da educação e do professor como esteios fundamentais para o soerguimento do país, uma vez que lhe cabia, em sua compreensão:

[...] formar, na juventude, vivos e persistentes hábitos de honestidade, dando-se-lhe uma têmpera sólida, que a proteja da indolência, do vício, da torpeza, das pequenas e grandes misérias de cada dia, e que ao seu coração imponha o inelutável rumo do bem. Cumpre, com a educação moral, criar, para a pátria, gerações cheias de equilíbrio. A pátria precisa de homens assim, firmes e corajosos, mas disciplinados e serenos, homens afeitos à ordem, aptos para a liberdade, e dignos da fortuna. Outro tema de essencial importância, é a figura do professor. O professor foi sempre um ser privilegiado. É que é dele, sobretudo dele, que depende a boa ou a má educação. Dele poderá vir para os homens e para as nações o maior bem ou o maior mal, porque é nas suas mãos que se coloca o grave ofício de afeiçoar e preparar o espírito da juventude. Pode-se dizer, portanto, rigorosamente, que uma nação será aquilo que dela fizerem os seus professores. As qualidades naturais que dele se devem exigir, a preparação especial que se lhe deve dar, os direitos e deveres e ainda as honrarias que lhe devem ser atribuídas, tudo constituirá matéria dedicada para o vosso estudo (CAPANEMA apud CURY, 2015, 408).

Alvitrava que o plano deveria constituir-se como um "corpo coeso de dispositivos legais" destinados a suplantar o caráter fragmentário e parcial das leis que vigoravam em todos os níveis de ensino do país (CAPANEMA, apud CURY, 2015, p. 4). Deste modo, em acordo com o encaminhamento proposto pelo ministro, o Conselho Nacional de Educação através de seu presidente Reinaldo Porchat afirmava o papel fiscalizador da União, reafirmando a jurisdição do Conselho na elaboração do Plano Nacional. Assim, as ponderações expressas por ele visavam avivar as prerrogativas outorgadas pela Constituição ao propor a criação e competência do órgão. (PORCHAT apud CURY, 2015, p. 409).

Com intuito de colaborar para a sua organização, concebido de forma participativa, foi proposto pelo ministro Gustavo Capanema, a realização de um inquérito sobre a educação nacional, a partir de janeiro de 1936. O inquérito foi publicado pela Imprensa Nacional em formato de livreto, intitulado Questionário para um inquérito (SCHWARTZMAN; BOMENY; COSTA, 1984). Argumentando em torno dos objetivos que mobilizaram a sua produção, os autores afirmavam que a proposta de realizar a consulta representou uma atitude "prudente", em função dos dissensos que envolviam as questões educacionais naquele contexto. Para os autores, "a ação educativa era vista como um recurso de poder e, portanto, ardorosamente disputada; o desacordo quanto às questões educacionais parecia expressar desacordos éticos e filosóficos insuperáveis" (1984, p. 176).

A ideia da participação de "todos" por meio da consulta, constituiu-se como estratégia que visou, não somente apaziguar os dissensos, mas também mapear as questões nacionais 
sinalizadas pelas instituições consideradas representativas da sociedade brasileira. Deste modo, o questionário funcionou como um instrumento consultivo direcionado à "opinião culta do Brasil", aos partícipes das instituições de ensino e das associações de prestígio educacional e intelectual a fim de contribuir para a elaboração de um plano nacional para a educação do país. Envidando esforços nesta direção, o questionário foi dividido em doze títulos e duzentas e treze questões em que abordava uma variedade de temas que envolvia desde a organização do ensino (primário, secundário e superior, emendativos ${ }^{7}$ e supletivos), o ensino religioso e o cinema educativo. Inquirindo, inclusive sobre: "Como pode ser definido o plano nacional de educação?" e "Qual deve ser a sua compreensão?" (INFÂNCIA E JUVENTUDE, n. 3, 1936, p. 162), entre outras perguntas em que se objetivava captar as aspirações e demandas dos diferentes setores da sociedade. Conforme Cury (2015)

Coube a Lourenço Filho propor o encaminhamento de elaboração do PNE e a ordem dos trabalhos. Assim, a 31 de março, tudo deveria estar pronto para ser enviada à Comissão de Redação. Essa teria dez dias para redigir o anteprojeto, distribuí-lo aos conselheiros cujas emendas seriam levadas às comissões competentes (2015, p.414-415).

Em sessão do CNE de 17 de fevereiro de 1937, o questionário foi aludido pelo ministro no sentido de ser instrumento colaborativo na elaboração do Plano. Destarte, entre os dias 15 e 17 de maio deste ano, as discussões foram intensificadas pelo Conselho Nacional de Educação, sendo aprovado e assinado o anteprojeto do plano com a inclusão das correções estabelecidas pela Comissão encarregada de sua redação. Após a entrega do anteprojeto ao ministro, o passo seguinte seria enviá-lo ao Presidente Getúlio Vargas e à Câmara dos Deputados. Assim, em 23 de agosto de 1937 foi realizada a primeira reunião da Comissão de Constituição e Justiça sob a presidência de Lourenço Baeta Neves (CURY, 2015). Após a discussão na Câmara dos Deputados, segundo Cury, agudizaram-se as visões dissonantes com relação à divisão das competências, bem como a outros pontos do anteprojeto que para os seus opositores feria a Constituição brasileira. Importa considerar que, embora o assunto tenha sido debatido, no correr do ano de 1937, o fechamento do congresso em 10 de novembro de 1937, após o golpe de Estado que instaurou o Estado Novo, enterrou em definitivo a expectativa de setores da sociedade de se constituir um Plano Nacional que se organizasse como diretrizes à educação nacional.

Importa considerar que os debates travados entre os anos de 1936 a 1937, no Conselho Nacional de Educação repercutiram pela imprensa e vice-versa. Exemplar nesta direção foram os artigos publicados na Revista Infância e Juventude. A partir da edição de número 3, de agosto de 1936, a revista publicou artigos alusivos ao ensino rural, os modelos escolares para os estados e o Distrito Federal, a questão em torno da educação das crianças anormais, as endemias rurais, a supressão do curso superior e as universidades, com destaque para as discussões em torno do Plano Nacional como elemento de civilização e modernização do país. No editorial, intitulado $O$ ensino na zona rural, os redatores J. Moreira de Sousa (diretor técnico), Stella Aboim (secretaria) e Renato Americano (diretor responsável e editor proprietário), anunciavam a importância do movimento do Ministério da Educação e Saúde Pública que recolhia dados por meio do questionário encaminhado às diversas corporações com o objetivo de pensar o anteprojeto que seria apresentado ao Poder Legislativo. Asseguravam, entusiasticamente, que havia "motivos sérios para crermos que ainda este ano teremos o 'Plano Nacional de Educação', a lei orgânica do ensino nacional, que tracejará as

\footnotetext{
$7 \mathrm{O}$ ensino emendativo seria a educação destinada às crianças consideradas anormais do físico, da inteligência e do caráter.
} 
linhas mestras, por onde se há de orientar a obra de educação e cultura de todo o país" (REVISTA INFÂNCIA E JUVENTUDE, n. 3, 1936, p. 162).

A perspectiva sinalizada no editorial que abriu a revista estava em acordo com a compreensão defendida pela Associação Brasileira de Educação quanto à natureza do Plano, como observamos no artigo publicado na seção Política, intitulado "O Plano Nacional de Educação" Como se pronunciou a Associação Brasileira de Educação que em alusão às perguntas: "Como pode ser definido o Plano Nacional de Educação? e "Qual deve ser a sua compreensão?", apresentava as considerações formuladas pela comissão da ABE, constituída por Adalberto Menezes de Oliveira, Francisco Venâncio Filho, Gustavo Lessa (redator), LaFayette Cortes e Octavio Martins. Assim, em resposta ao questionário, a comissão da Associação Brasileira de Educação (ABE), optou por responder de forma global e integrada deixando entrever a existência de dois pontos de vista antagônicos com relação ao Plano. $\mathrm{O}$ primeiro, trazia a compreensão que o plano deveria assumir um caráter de código nacional de ensino e; o segundo, que asseverava que o plano deveria funcionar preceituando instruções ou indicações quanto à educação nacional, como diretrizes para o ensino (INFÂNCIA E JUVENTUDE, n. 3, 1936, p. 162). Quanto ao encaminhamento que tomou forma e corpo na Câmara, o editorial reafirmava a compreensão de que:

[...] já agora se pode dizer que um Código de Ensino para todo o Brasil será francamente inconstitucional, além de ser profundamente nocivo, conforme o demonstra, entre outras razões, o clamor levantado contra as seriações rígidas e os programas minuciosos impostos a todo o país pelas diferentes reformas educacionais elaboradas durante o período republicano (INFÂNCIA E JUVENTUDE, n. 3, 1936, p. 162).

A argumentação em torno dos princípios definidos pela Carta Constitucional de 1934 foi exortada no sentido de que era conferido à União, tão somente "o poder de traçar as diretrizes da educação nacional". Desta forma, "o Plano Nacional de Educação não poderia conter mais do que diretrizes", pois como código de ensino seria "inconstitucional", por apresentar, entre outros aspectos, seriações rígidas e programa único a ser imposto a todo o país. Portanto, cabia aos Estados e ao Distrito Federal "o poder de organizar e manter sistemas educativos" respeitando as diretrizes estabelecidas na Constituição (INFÂNCIA E JUVENTUDE, n. 3, 1936, p. 162). A prerrogativa sinalizada considerava os pontos básicos do questionário e, a partir deles, estabelecia um conjunto de diretrizes que deveria ser incorporado ao Plano a ser redigido pelo Conselho Nacional de Educação.

Há de notar que a comissão instituída pela Associação Brasileira de Educação elaborou um conjunto de diretrizes a serem entregues ao Conselho Nacional de Educação para integrar o projeto do Plano. Dentre os artigos propostos, previa em seu artigo primeiro que: "Na organização dos seus sistemas educacionais, os Estados e o Distrito Federal gozarão de plena autonomia, ressalvados os princípios constitucionais e as diretrizes traçadas na presente lei" (ano, no 3 p. 164). As diretrizes propostas encaminhavam proposições destinadas a assegurar, com base na Carta Constitucional: autonomia aos Estados e ao Distrito Federal; o ensino primário integral gratuito e de frequência obrigatória e que caberia às legislações estaduais definirem a duração escolar. Assim, o Plano Nacional de Educação precisaria assumir um caráter "dinâmico" em que fosse traçado um "programa de ação federal e de subvenções aos Estados para o desenvolvimento dos seus sistemas educacionais", a partir da fiscalização da União (INFÂNCIA E JUVENTUDE, n. 3, 1936, p. 162-163).

Embora a revista não tenha publicado integralmente o questionário do inquérito, deu destaque às reflexões elaboradas pelos educadores Isaias Alves, Leoni Kaseff, J. Moreira de 
Souza, Gustavo Capanema, Teixeira de Freitas, Padre Arlindo Vieira, Reynaldo Porchat, da Associação Brasileira de Educação, do Instituto Histórico e Geográfico Brasileiro e a sua própria opinião exposta através dos seus editoriais. Ainda na edição de agosto de 1936, a revista publicou o projeto de lei que a Câmara dos Deputados apresentou à Comissão de Instrução Pública do Império, em 1826. O projeto foi publicado integralmente, sendo fracionado em três números da revista: na terceira, na quarta e na quinta edições de 1936. Quanto ao intuito da publicação afirmavam que era o de "abrir campo a discussão", onde:

Preocupada em contribuir, da melhor forma possível, para que ao Brasil seja dado um Plano Nacional de Educação, ao nível de sua cultura e de suas necessidades econômico-sociais, INFÂNCIA E JUVENTUDE envidará quanto esforço estiver ao seu alcance, contanto que se esclareçam, devidamente, com dados positivos e orientação, serena e imparcial, os que vão ter aos ombros a magma tarefa (INFÂNCIA E JUVENTUDE, n.3, p. 172).

Na seção de Política, o professor Isaias Alves membro do Conselho Nacional de Educação, defendia a urgência de se instituir a formação cultural do povo sendo necessário, para isso, que se criassem escolas no país. Analisando o quantitativo de crianças na e fora da escola, afirmava ser urgente que o Plano Nacional apresentasse metas para que de fato a educação escolar chegasse a todos. Para Isaias Alves, o investimento na educação de adultos deveria ir além das universidades, ao criar formas de continuidade de estudos para adultos em todos os níveis do conhecimento. Neste sentido, Alves (1936), argumentava ser necessária uma formação adequada aos imperativos da indústria, sendo para isto, empreendida uma habilitação profissional que promovesse a integração do jovem e adulto operário às novas formas de produção, especialmente em países, como o Brasil, que produziam taxas expressivas de desemprego. Sua argumentação valorizava tanto o trabalhador quanto o estudante superior. Alves acreditava que a educação não poderia findar com o término de um curso, deveria acompanhar o estudante durante a profissionalização e após, oferecendo-lhe meios de permanência e atualização na profissão escolhida. Para ele, a formação moral e intelectual do homem era a forma de se garantir a democracia. Assim caberia às autoridades, conceder aos nativos e imigrantes uma educação profissional e contínua, bem como meios para a nacionalização do brasileiro e do estrangeiro, como forma de pertença e aprimoramento da civilização.

O Plano Nacional de Educação, cuidando do ensino nas zonas rurais, da alfabetização das massas, da disciplina da escola secundária, não lançará bases firmes para cultura nacional, sem organizar solidamente os estudos universitários, em que os espíritos amadurecidos complete a sua educação científica e literária e em que os jovens de alto talento aprendam a sentir os segredos de Camões e de Newton, de Schiller e de Miguel Ângelo, de Pascal, de Einstein, de Virgílio, de Aristóteles, de São Tomás (ALVES, n. 5 1936, p. 304).

Na perspectiva de colaborar com as discussões, o professor Leoni Kaseff, membro da Associação Brasileira de Educação, da Academia de Ciência da Educação, assistente técnico da Universidade do Rio de Janeiro, publicou no sexto número da Revista Infância e Juventude (1936), o seu primeiro artigo intitulado Plano Nacional de educação - suas oportunidades e objetivos primaciais. Nele argumentava sobre a finalidade do Plano como elemento capaz de 
colaborar para a "reconstrução educacional" e, por conseguinte, do país. Marcando seu lugar de fala no debate afirmava que:

$\mathrm{Na}$ reconstrução educacional do país, que se projeta, nenhum dos meios eficientes da reforma deverá ser esquecido. Mas é preciso não olvidar que a mobilização dos fatores de renovação seria incompreensível e ineficaz sem a previa e exata definição das propostas alcançar. Não basta elaborar um plano teoricamente perfeito, que por seu artificialismo, não se enquadre no conjunto da vida e dos interesses reais da nação. Um plano supõe a propositura de claros fins a atingir, para as quais representa um sistema de meios e que, por seu turno, pressupõem o conhecimento preciso das necessidades a atender. O Plano Nacional de Educação deverá, portanto, rigorosamente ajustar-se ao quadro das realidades brasileiras e não constituir uma peça à parte, sem articulação objetiva com os nossos problemas, um simples painel decorativo da nossa civilização (KASEFF, 1936, n. 6, p. 366).

Defendia que somente a partir da identificação das demandas e dos problemas nacionais poderíamos elaborar um plano consciente e eficaz. Para isto, propunha a necessidade de se construir uma consciência cívica, profissional e sanitária propondo, para isto, a instalação de uma diretriz a ser traçada de acordo com a diversidade regional do povo brasileiro. Considerava necessário que se pensasse um plano capaz de organizar os meios projetados na evolução educacional, como forma de disponibilizar à sociedade uma educação baseada na formação intelectual e profissional. Com este propósito, o Plano deveria ser construído em terreno brasileiro e para os brasileiros, de forma que não se optasse por realizar cópia inadequada à Pátria. Sobre o que caracterizou como "os reais" objetivos e finalidades do plano, Kaseff afiançava que "os povos atravessam duas fases, nitidamente distintas, na evolução dos seus modernos interesses educacionais: o de propaganda e controvérsia, e o de planificação" (1936, n. 6, p. 365-366). Nesta direção, avalizava que:

A primeira dessas fases - cuja característica essencial é o entusiasmo apostólico pela difusão das novas ideias, nem sempre temperado por um claro senso realista - pode considerar-se que já passou, na atualidade pedagógica do nosso país. Daí não se segue que se devam condenar todos os movimentos destinados, simplesmente, a propagandear vantagens da instrução, ou a recomendar novos rumos que se lhe possam imprimir. Conclui-se, apenas, que a oportunidade das realizações chegou, que é tempo, agora, de agir construtivamente, de lançar os fundamentos da escola brasileira e de erigir, sobre esses sólidos alicerces, não sobre a areia movediça de alienígenas concepções, o autêntico edifício da educação nacional (KASEFF, 1936, n.6, p. 365).

Quanto a isto, identificava ser imperativo: "a formação de uma consciência sanitária, de uma consciência cívica, e de uma consciência profissional na promoção da educação das novas gerações brasileiras". Para ele era objetivo da educação semear uma consciência sanitária individual e coletiva, na escola e no lar. A preocupação em torno de uma consciência sanitária crescia nos discursos e debates educacionais. Era primordial cuidar das futuras gerações, construindo uma base sólida pela educação. Fomentar uma educação sanitária pela escola era a forma de se prevenir possíveis epidemias que assolavam o país, onde: "A 
educação sanitária representa um dos problemas de maior gravidade, cuja solução não seria lógico, nem patriótico, descurar no plano nacional de educação". Outro problema que assumiu centralidade em seus escritos foi a educação profissional. Ao argumentar em torno da economia do país, Kaseff (1936) destacou a situação de miséria da população, sobretudo, das rurais. Para ele, a falta de condições para custear os cuidados básicos e sobrevivência saudável do corpo, da alimentação, interferia na vida individual e coletiva do cidadão. Defendia que a pobreza não poderia ser resolvida somente com os cuidados com a higiene, era preciso promover investimentos na formação moral e intelectual do trabalhador. Outro aspecto que destacou foi a educação moral. Sobre o tema, o educador considerou primordial o ensino das tradições e heranças culturais, com intuito de semear uma "consciência de unidade nacional" como desenvolvimento da moral (1936, n. 6, p. 367).

Assim, consideramos que os temas encampados por Kaseff (1936) estavam em acordo com as formulações mobilizadas pelos intelectuais reformadores envolvidos diretamente com a elaboração do Manifesto dos Pioneiros da Educação Nova de 1932 quanto, por exemplo, às críticas formuladas ao artificialismo, a inadequação e a superficialidade dos projetos no âmbito da educação nacional, bem como da centralidade atribuída à educação como mola impulsionadora dos progressos do país. Assim, a elaboração do Plano Nacional de Educação representava a possibilidade de se empreender diretrizes que pudessem expressar os anseios desse setor intelectual. A pauta destacada por ele indicia, em nossa compreensão, a sua filiação às ideias propugnadas pela Associação Brasileira de Educação (ABE). Nesta direção, assevera Carvalho que:

Torna compreensível a relevância que tem o tema relativo à função formativa da escola secundária pensada como agência de constituição, homogeneização e disseminação de uma cultura média. Explica a posição estratégica da questão da formação de professores da escola primária, pensados como 'organizadores da alma popular'. E, finalmente, esclarece a concepção de ensino universitário do grupo de Vicente Licínio Cardoso, nucleado na Seção do Ensino Superior do departamento carioca da ABE, que propunha a Universidade como 'usina mental' em que deveriam formular-se 'programas de vida' para a nação. $\mathrm{Na}$ conjunção dessas propostas, possibilita compreender a permanência de uma rígida demarcação entre dois universos: o relativo à chamada 'educação de elite' e o destinatário à 'educação do povo', assegurando-se prioridade estratégica ao primeiro (1997, p. 126 - grifos da autora).

Para Bomeny (2003, p. 31) na construção de relações estreitas com os poderes políticos do país, a ABE teria empreendido um "desvio" dos ideais defendidos pelos seus fundadores que, em concordância com os ideais de transformação do país, criaram, em outubro de 1924, a instituição na cidade do Rio de Janeiro. A ideia de sua criação tomou forma a partir de uma reunião promovida pelo professor Heitor Lyra da Silva e por intelectuais preocupados com a reorganização da educação nacional, entre eles: Everardo Backheuser, Edgar Sussekind e Francisco Venâncio Filho. Na ocasião, discutiram sobre a possibilidade de se conceber uma Federação de Associações de Ensino de caráter apolítico. Sem condições efetivas para assumir essa empreitada, criaram, meses depois, a Associação Brasileira de Educação (ABE) na Escola Politécnica do Rio de Janeiro. Concebida como "instância de articulação", promoção e propaganda do movimento de renovação educacional entre as décadas de 1920 e 1930, a ABE, visou produzir inquéritos, revistas, debates, cursos e congressos destinados a incidir sobre a produção de políticas educacionais em âmbito nacional (CARVALHO, 1997, p. 115). 
A publicação do Manifesto dos Pioneiros da Educação Nova, em 1932, por sua vez, colocou em realce a ruptura existente no interior da $\mathrm{ABE}$ entre duas concepções que se digladiavam. Por um lado, pela presença dos que defendiam o ideal apolítico e, por outro, dos que, em contrapartida, corroborava da convicção acerca do papel a ser desempenhado pela associação na promoção de ações destinadas ao desenvolvimento da política educacional. Neste particular, a instituição funcionava como um ambiente propício à promoção de uma campanha nacional. Carvalho (1986) aponta que para o educador Nóbrega da Cunha a aproximação aconteceu de forma contrária, pois, ao lançar o Manifesto, o grupo de intelectuais da Associação Brasileira de Educação (ABE) consolidou uma aversão à relação partidária com o governo provisório, fato este que gerou um desconforto entre os membros da ABE que defendiam o ideal apolítico proposto por Heitor Lyra. Esta associação constituiu-se como um campo de debates e disputas pelo desenvolvimento da educação nacional, promovendo conferências de caráter nacional.

Por sua vez, em resposta ao pedido do Ministério de Educação, o Instituto Histórico e Geográfico Brasileiro (IHGB) sintetizou algumas considerações referentes ao Plano, relatadas por Basílio Magalhães na oitava edição da revista. Assim, para cada questão foram apresentadas sínteses das proposições do IHGB. Dentre eles: a) Definição, compreensão, e duração do Plano Nacional de Educação; b) Princípios que devem orientar a educação do Brasil; h) Certificados, diplomas e títulos escolares; i) Denominações dos institutos de ensino (MAGALHÃES, 1937, n. 8).

Para responder a primeira questão que tratava da definição do Plano Nacional de Educação, a comissão do Instituto Histórico e Geográfico Brasileiro argumentou de acordo com os estudos de Montpellier que, "o Plano Nacional de Educação, que só se pode definir como um 'conjunto de medidas tecnicamente organizadas com o efeito de se conseguir a culturalização integral do povo brasileiro', deve compreender tanto as atividades escolares quanto as atividades extraescolares de influência educativas". Defendiam ser a educação responsabilidade da família e do Estado a educação, devendo ser uma formação "integral do povo brasileiro" (MAGALHÃES, 1937, n.8, p. 511), envolvendo os conhecimentos sobre a saúde, mas também dos estudos de elementos que pudessem aumentar o nível mental do povo. Como modelo para os Estados e municípios, caberia à União a organizar institutos primários, secundários, superiores e supletivos. Sobre o item (b) que se referia aos princípios do Plano. Argumentava que:

Do próprio questionário infere-se não somente o que é desejo do atual governo que o Plano Nacional de Educação se enquadre nas normas do 'sindicalismo', recentemente oficializado no Brasil, como também que ele atenda às regras do 'tailarismo' e do 'faiolismo', se não às injunções técnicas da hodierna 'racionalização' (MAGALHÃES, 1937, n. 8, p. 512).

Em sua concepção tanto a racionalização quanto o sindicalismo eram essenciais para a construção de um plano que estivesse de acordo com a atualidade da época. Ou seja, era preciso priorizar as mudanças econômicas, culturais e sociais para criar um plano que pudesse instruir a população. Para isto, Magalhães (1937) ressaltou a valorização da inteligência, compreendida como parte fundamental da natureza humana que para ser desenvolvida prescindia do ensino técnico e da cultura. Defendendo a ordem, a disciplina moral da família para formar a verdadeira "alma brasileira" (1937, n. 8, p. 513). Quando ao ensino religioso, afirmava ser um assunto delicado, pois "não deve sair nunca da alçada da família, nele não devendo jamais intervir o Estado, principalmente por se tratar de um país que não tem religião oficial" (MAGALHÃES, 1937, n. 8, p. 513). Em respeito à Constituição de 1934, o relator defendia que as aulas deveriam ser ministradas por um educador de qualquer religião e que seriam facultativas. Embora a revista tenha disponibilizado apenas alguns trechos das 
respostas formuladas pelo Instituto, consideramos que estas constituíram-se de grande relevância para a formulação da proposta do PNE.

Após os apontamentos de Magalhães a revista publicou, em seu número nove, o discurso do ministro da educação Gustavo Capanema. A preleção proferida na sessão de instalação do Conselho Nacional de Educação marcou o início das atividades de elaboração do anteprojeto do Plano Nacional de Educação. Na ocasião, o ministro se comprometeu a cooperar com o Conselho Nacional de Educação para a sua construção.

Para vós, vão ficar, agora, voltados os olhos quantos, com lúcida consciência e sincero amor, estejam trabalhando pelo Brasil, na multiplicação de seus bens, no fortalecimento de suas armas, no aprimoramento de sua cultura ou na elevação de suas virtudes, em qualquer domínio que seja de suas atividades, porquanto hão de todos estar certos de que este trabalho, por mais reunido que seja, não produzirá a soma dos frutos esperados, se a educação for pouca e de fraca influência, mas darás resultados milagrosos, transformando os nossos planos e esforços em coisas reais, úteis e bela, uma vez que essa mesma educação precise o sentido, anime o ímpeto e mobilize os instrumentos numerosos e adequados (CAPANEMA, 1937, n.9, p. 547-548).

O ministro Gustavo Capanema afirmava a difícil missão que o Conselho Nacional de Educação vinha travando para realizar, pela primeira vez, "uma lei de conjunto sobre a educação" (CAPANEMA, 1937, n. 9, p. 548). Deste modo, o Plano tinha o objetivo de organizar as leis já existentes, aprimorando-as e criando outras para unificá-las em um único documento que pudesse envolver do ensino primário ao superior. Para Capanema (1937) a questão do Plano Nacional de Educação era a da educação intelectual. Enaltecendo para isto o ensino superior e a urgência na sua ampliação, especialmente quanto ao ensino de Filosofia, Letras e Artes; no ensino secundário, maior valorização das ciências e dos ensinos das "velhas, altas e egrégias humanidades (1937, n. 9, p. 549); o ensino profissional nas modalidades: industrial, agrícola, doméstico e o desenvolvimento estrutural para cada área, criando um curso relacionado a melhoria do trabalho e do trabalhador. Quanto ao ensino primário:

[...] cumpre incentivar intensamente em todo o país, pois cerca de $60 \%$ de nossa população infantil em idade escolar não dispõe de escola, bem é que se padronizem, ainda com um mínimo de característicos, diferentes tipos de cursos, que possam ser adequadamente e com facilidades adotadas nos vários pontos do território nacional, nas zonas urbanas e rurais, afim de que, fazendo-se rápida difusão da educação primária se facilite a formação de um fundo comum na enorme e rica variedade psique brasileira (CAPANEMA, 1937, n. 9, p. 550).

Em sua apreciação, o ministro Gustavo Capanema evidenciava a situação da infância e da juventude - expressa no percentual indicado - que não dispunha de escola, enfatizando a urgência em se proceder à criação de diferentes iniciativas a fim de sanar o déficit de escolarização e de educação do país, enfatizando para isto, o importante papel do professor.

$\mathrm{Na}$ edição de maio de 1937, a revista publicou o artigo de Teixeira de Freitas, presidente da Associação Brasileira de Educação, em 1937, e diretor de estatística do Ministério de Educação. Seu nome aparece como colaborador efetivo desde os primeiros números no ano de 1936, mas somente na décima primeira edição (1937), publicou um artigo 
como representante da $\mathrm{ABE}$, por ocasião da posse do professor Lourenço Filho na direção do Departamento de Educação. Em seu discurso, Freitas enaltece o trabalho realizado pelo ministro demonstrando o que considerou serem "os grandes esforços" para efetivação do Plano Nacional de Educação, da criação de um financiamento para educação e a nova fase do Departamento Nacional de Educação com a nomeação de Lourenço Filho para o cargo de diretor da pasta (INFÂNCIA E JUVENTUDE, 1937, n. 11).

Em sua argumentação, Teixeira de Freitas elenca sete pontos cardinais em torno da educação no país, a saber: a notabilização profissional do magistério primário a ser pensado, por meio de um sistema de remuneração que considerasse o tempo de serviço, o merecimento e outros aspectos; a nacionalização e gratuidade do material didático para a educação elementar; a organização, publicação e distribuição gratuita da Biblioteca Brasileira de Educação Popular; a distribuição popular e gratuita da Revista Nacional de Educação, a instituição de colônias-escolas e vilas-escolares como instrumento de educação rural e a promoção de acordos inter administrativos (FREITAS, 1937, n. 12, p. 822).

As ponderações de Teixeira de Freitas, Leoni Kaseff, Isaias Alves, bem como as encaminhadas pela Associação Brasileira de Educação e Instituto Histórico e Geográfico Brasileiro apresentavam elementos comuns quanto à formulação de propostas quanto a elaboração do Plano Nacional de Educação. Conceberam o Plano a partir da projeção de metas que deveriam ser organizadas em sintonia com a realidade brasileira. Nesta direção, a revista constituiu-se como veículo importante na composição das redes estratégicas mobilizadas pelo Ministro da Educação, Gustavo Capanema para fazer força frente aos dissensos em torno da educação. A criação da Revista dois meses após a apresentação do questionário do inquérito, em 1936, e a sua extinção meses após a apresentação do Plano Nacional de Educação pelo Conselho Nacional de Educação, constitui-se em indícios que não devem ser negligenciados.

\section{Considerações finais}

Ao longo de suas edições, a Revista Infância e Juventude propôs e fez circular debates em torno da educação nacional e de temas cardinais. Importa considerar que a obrigatoriedade constitucional de se empreender a elaboração de um Plano Nacional de Educação fazia parte das bandeiras empunhadas pelos educadores identificados com o movimento da Escola Nova. Os artigos publicados cooperam para pensarmos sobre a atuação do periódico na divulgação dos ideais dos educadores e dos representantes do Estado na formulação de ações propositivas e influentes na sociedade e na política. Assumindo posição frente às questões nacionais, jogando luz sobre um conjunto de questões, esses intelectuais - colaboradores flutuante e efetivo - independente das dissensões existentes, em alguns casos, comungavam de um ideal: modernizar e civilizar o país pela educação.

Nas diferentes respostas ao questionário do inquérito enviado pelo Ministério da Educação e Saúde Pública, publicadas pela revista, foi possível mapear temáticas relacionadas ao ensino primário gratuito e obrigatório, a reforma do ensino secundário, o ensino profissional, a educação rural, o ensino secundário e superior, a formação de professores, a educação de jovens e adultos, o desenvolvimento das universidades, a autonomia dos estados e do Distrito Federal quanto à organização dos seus sistemas educacionais, entre outros. $\mathrm{O}$ destaque atribuído a esses assuntos demonstra a emergência que determinadas questões assumiram frente à perspectiva que propunha promover a reconstrução do país, via a reconstrução da educação. A crença que movia tal empreitada assentava-se numa matriz nacionalista, no empenho em concretizar um ensino integrado entre o primário, o secundário e o profissional, como partes de um conjunto de metas e diretrizes a serem seguidas por todo 
país, sendo a produção do Plano Nacional de Educação concebida como movimento estratégico fundamental.

A análise das edições da revista permitiu captar as intenções que, em nossa compreensão, motivaram a criação da revista e, posteriormente, a sua extinção. Parece-nos plausível considerar, entre esses aspectos, o propósito de promover o questionário do inquérito encaminhado pelo ministro Gustavo Capanema. Associado a isto, o interesse de contribuir mais amplamente na veiculação de ideias e na formulação de projetos educacionais no âmbito nacional.

Nesse sentido, este artigo investiu na compreensão da Revista Infância e Juventude, como arena de disputa, debate e circulação de propostas, projetos e ações educacionais e de movimentação dos intelectuais. Buscou-se captar dissensos e consensos que se evidenciaram, em alguns casos, na análise dos artigos selecionados e na composição dos eixos discursivos que deram forma às distintas edições da revista. Com esse intento, objetivamos analisar a composição de seu corpo editor, seus colaboradores e as possíveis relações instituídas com o contexto político da época. Percebemos a defesa do corpo editorial da revista e dos seus colaboradores, no sentido de que fosse criado um conjunto de metas para a educação capaz de formar moral e intelectualmente a infância e a juventude brasileira.

$\mathrm{Na}$ composição dessa trama consideramos que o periódico procurou pautar uma agenda de questões a serem previstas na formulação do Plano Nacional de Educação que estava sendo debatido nas sessões do Conselho Nacional de Educação. Embora o Plano tenha permanecido sem andamento na Câmara dos Deputados por vários anos, contrariando a expectativa expressa por Gustavo Capanema em seu discurso na sessão de assinatura do anteprojeto do Plano no Conselho Nacional de Educação, em maio de 1937, construir esforços que permitam historicizar a composição desses debates e embates parece-nos relevante à medida que revelam as linhas de força que os compuseram, permitindo deslocar o foco para distintas disputas. Nesta direção, consideramos que as ações estratégicas e os jogos de poder não se localizaram em um único lugar, mas mobilizaram e ocuparam a cena a partir da atuação de diferentes atores sociais que, por muitas vezes, são negligenciados pela história.

\section{Referências}

ALVES, Isaias. O ensino profissional e o Plano Nacional de Educação. In: INFÂNCIA E JUVENTUDE, Rio de Janeiro, n. 4, ano 1, Setembro de 1936.

ALVES, Isaias. Educação de Adultos no Plano Nacional de Educação. In: INFÂNCIA E JUVENTUDE, Rio de Janeiro, n. 5, ano 1, Outubro de 1936.

BOMENY, Helena. Os Intelectuais da Educação. Rio de Janeiro: Zahar, 2003.

CAMARA, Sônia. Reinventando a escola: o ensino profissional feminino na Reforma Fernando de Azevedo de 1927 a 1930. Rio de Janeiro: Quartet, 2013.

CAMPOS, Regina Helena de Freitas. Helena Antipoff: razão e sensibilidade na psicologia da educação. Estudos Avançados, v. 17, n. 49, p. 209-231, 2003. https://doi.org/10.1590/S0103$\underline{40142003000300013}$

CAPANEMA, Gustavo. Conselho Nacional de Educação: Discurso pronunciado na sessão solene de sua instalação. In: Infância e Juventude, Rio de Janeiro, n. 9, ano 1, fevereiro de 1937. 
CAPELATO, Maria Helena. O Estado Novo: o que trouxe de novo. In: Ferreira, Jorge; DELGADO, Lucilia de Almeida N. (orgs.). O Brasil Republicano. O tempo do nacionalestatismo 2. Rio de Janeiro: Civilização Brasileira, 2012.

CARVALHO, Marta Maria C. de. Educação e Política nos anos 20: a desilusão com a República e o entusiasmo pela educação. In: De LORENZO, Helena; COSTA, Wilma Peres (orgs.). A década de 1920 e as origens do Brasil moderno. São Paulo: Fundação Editora da UNESP, 1997.

CARVALHO, Marta Maria C. de. Molde Nacional e Fôrma cívica: higiene e trabalho no projeto da Associação Brasileira de Educação (1924-1931). São Paulo, Tese (Doutorado) Faculdade de Educação da Universidade de São Paulo, 1986.

CAVALCANTI, Maria Juraci Maia. Algumas indagações sobre o silêncio em torno da $6^{\mathbf{a}}$ Conferência Nacional de Educação. History of Education Journal, v. 4, n. 8, p. 193-209, 2000.

CELESTE FILHO, Macioniro. Leigos e Católicos em disputa pela Escola Nova no Brasil. VIII Congresso Brasileiro de História da Educação - Matrizes interpretativas e internacionalização - Universidade Estadual de Maringá. Maringá, 2015.

CERTEAU, Michel de. A invenção do cotidiano. 1. Artes de fazer. Petropólis, Rio de Janeiro: Vozes, 2011.

CURY, Carlos Roberto Jamil. O Plano Nacional de 1936/937. In: Educativa, Goiânia, v. 17, n.2, p. 396-424, jul./dez. 2015.

CURY, Carlos Roberto Jamil. Educação e direito à educação no Brasil. Um histórico pelas Constituições. Belo Horizonte: Mazza Edições, 2014.

LUCA, Tânia Regina de. História dos, nos por meio dos periódicos. In: PINSKY, Carla Bassanezi. (org.). Fontes Históricas. São Paulo: Contexto, 2014.

FREITAS, Teixeira de. A atuação do Ministro Capanema e a nova fase do Departamento Nacional de Educação. In: Infância e Juventude, Rio de Janeiro, n. 11, ano 1, Abril de 1937.

FREITAS, Teixeira de. A propósito do Plano Nacional de Educação. In: Infância e Juventude, Rio de Janeiro, n. 12, ano 1, Maio de 1937.

INFÂNCIA E JUVENTUDE. Rio de Janeiro, 1936-1937.

INFÂNCIA E JUVENTUDE. Rio de Janeiro, n. 3, ano 1, Agosto,1936.

INFÂNCIA E JUVENTUDE. Rio de Janeiro, n. 6, Novembro de 1936.

INFÂNCIA E JUVENTUDE. Rio de Janeiro, n. 11, Abril de 1937.

KASEFF, Leoni. Plano Nacional de Educação: Suas oportunidades e objetivos principais. In: Infância e Juventude, Rio de Janeiro, n. 6, ano 1, Novembro de 1936.

KASEFF, Leoni. O ensino emendativo no Plano Nacional de Educação. In: Infância e Juventude, Rio de Janeiro, n. 12, ano 1, Maio de 1937. 
MAGAlHÃES, Basílio. Plano Nacional de Educação. In: Infância e Juventude, Rio de Janeiro, n. 8, ano 1, Janeiro de 1937.

PANDOLFI, Dulce Chaves. Os anos 1930: as incertezas do regime. In: Ferreira, Jorge; DELGADO, Lucilia de Almeida N. (orgs.). O Brasil Republicano. O tempo do nacionalestatismo. Rio de Janeiro: Civilização Brasileira, 2012.

POLETTI, Ronaldo. Coleção Constituições brasileiras 1934, 3. ed. - Brasília: Senado Federal, Subsecretaria de Edições Técnicas, 2012.

SCHWARTZMAN, Simon; BOMENY, Helena Maria B.; COSTA, Vanda Maria R. (orgs.). Tempos de Capanema. Rio de Janeiro: Paz e terra; São Paulo: Editora da Universidade de São Paulo, 1984.

VELLOSO, Mônica. Uma configuração do campo intelectual. In: Oliveira, Lúcia Lippi; VELlOSO, Mônica Pimenta; GOMES, Ângela Maria de Castro. Estado Novo: ideologia poder. Rio Janeiro: Zahar Ed., 1982.

SKALINSKI JUNIOR, Oriomar; RUCKSTADTER, Flávio Massami Martins. A resposta de Alceu Amoroso Lima ao inquérito expedido pelo ministério da Educação e Saúde Pública em 1936: um intelectual em defesa dos "princípios pedagógicos" católicos. In: Inter-Ação, Goiânia, v.41, n.1, p.43-64, jan./abr. 2016. https://doi.org/10.5216/ia.v40i3.35869 